portable anaesthetic apparatus. I am sure the Malaysian Oxygen Company's parent company in London would be prepared to make a similar stand for their equipment if requested.-I am, etc.,

T. H. S. BurNs.

Department of Anaesthetics,

St. Thomas's Hospital,
I ondon S.E.1.

\section{Perfusion Treatment of Cancer}

Sir,-Recently while carrying out perfusion on a case of inoperable carcinoma of the mandible the following observation was made. A male patient aged 82 was admitted with an extensive growth of the left mandible, cheek, tongue, and floor of the mouth, which had previously been treated with telecobalt therapy. The histology revealed a squamouscell carcinoma. It was decided to infuse the affected area with 5-fluorouracil through a catheter inserted into the left superficial temporal artery. During the procedure the catheter was advanced downwards and $1 \mathrm{ml}$. of Disulphine blue injected to outline the area of distribution. In order to confirm that the catheter was not in the common carotid artery the fundus on that side was examined. However, it was found that the vessels of the left fundus were stained blue. The catheter was then withdrawn by $2.5 \mathrm{~cm}$.

From this observation we feel that a simple clinical method would be to observe the fundus on the same side, as the catheter is advanced and the dye introduced. The point at which the vessels of the fundus stained blue would denote that the end of the catheter was sited at or just below the level of the carotid bifurcation. Withdrawing the catheter by approximately $2 \mathrm{~cm}$. would then ensure that the catheter was not in the common carotid artery.-I am, etc.,

$$
\begin{aligned}
& \text { E.N.T. Department, } \\
& \text { Dudiey Road Hospital, } \\
& \text { Birmingham 18. }
\end{aligned}
$$

\section{Treatment of Obesity}

SIR,-In your recent leading article on obesity (19 December, p. 1543) and in many other papers and letters on this all-important subject scant attention seems to have been paid to the essential factor of calorie output or metabolic rate in coming to grips with the problem.

On rare occasions I have come across instances where a stone or more has been lost over a period of two to three months without discomfort by simple expedients such as abandoning a waistcoat, a vest, a regular hot-water bottle, the additional blanket on the bed, or spending less time in sleep.

Calculation of the energy outputs of physical exercise from gymnasium activities to mountain climbing are depressingly small, and in any event such infrequent feats of endurance are quite beyond the average obese subject. But the regular daily and nightly measures listed above cost nothing and can be regarded as practical politics.

Most of us would be glad to hear of the results of any course of work directed towards stepping up metabolism and consequent loss of weight without resorting either to drugs or unduly irksome diets. Such research should prove relatively simple to carry out, requiring little apparatus, and at the same time amply rewarding. - I am, etc., Aylesbury, Bucks.

$$
\text { J. G. C. Spencer Bernard. }
$$

\section{Work for Married Women Doctors}

Sir,-At a time when the shortage of doctors is approaching crisis proportions the problems facing married women doctors in finding part-time work have received no publicity at all in your columns. The wastage of graduates among women in the same position as myself (through no fault of our own) must be considerable.

During the past two years I have made intensive and unremitting efforts to find suitable work, but have not succeeded. However, during this time I have reviewed the various problems and feel that they are worthy of note. My conclusion is that at the present time I see no possibility of my practising medicine again. In common with many graduates, I find being a full-time housewife exceedingly boring and I can only hope to find other work in which my very specialized medical training may be of use. Preliminary inquiries reveal that this will be difficult.

The results of my inquiries are as follows. The part-time posts available are:

(a) Regular work

Local authority work (Health Clinics etc.)

Hospital posts (clinical assistantships and part-time casualty officers)

Family Planning Association Clinics

General-practitioner assistantships

(b) Irregular work

Local authority work

Locums-general practitioner or hospital.

The main problem is that there are extremely few regular posts available. Local health authorities where possible prefer to employ full-time doctors. The vast majority of hospital posts are offered to general practitioners almost exclusively. Of equal importance is the fact that, unless one regards two hours' travelling time for a one-hour surgery "locum" as worthwhile, it is necessary to have a car. It is quite impossible to earn enough to buy and run a car oneself, working part-time, and so the few posis there are are available only to those women who have a car for their own use. Irregular work can be done only by those women who-(1) have resident domestic help (or the equivalenti.e., a relation) ; or (2) have few family commitments; or (3) have a husband free and willing to take over domestic chores at short notice.

Very few people to whom I have spoken realize that domestic help can be employed only on a regular basis, and therefore, unless one has regular work, one cannot have extra domestic help.

I have given a great deal of thought to these problems, but have thought of only one solution. Many specialties could be very well served by two (or more) part-time S.H.O.s replacing an existing S.H.O. (full-time). Such specialties I suggest are-geriatrics; casualty ; long-stay orthopaedic, medical, and general surgical cases ; E.N.T.; and possibly some others. For such posts a car would not be necessary, and so many more women would be eligible to apply. This would help to ease the shortage of junior hospital doctors. I should be glad to hear from anyone who is interested in this problem.-I am, etc.,

$$
\text { Richmond, Surrey. VALERIE Y. MUIR. }
$$

\section{Hazards in Hospital for Ex-smokers}

Sir,-A friend of mine who gave up smoking six months ago is at present in hospital for a minor operation. Since his operation he has started to smoke again. Exsmokers who are admitted to hospital are probably exposed to greater temptation to resume the habit than at any other time because of pain, slceplessness, boredom, or simply because they have to lie all day and watch others smoke. As the medical profession is the champion of the anti-smoking campaign, it is ironical that a relapse should be associated with a stay in hospital. As ex-smokers are probably bored more easily than smokers, and this boredom is most likely to lead to resumption of the habit, particular attention should be paid to them in hospital, if only to ensure that they are adequatcly occupied, encouraged to persevere, and not given beds next to heavy smokers. -I am, etc.,

Norwich.

SYlvia T. LAND.

\section{Gregor Mendel}

SIR,-The excellent reproduction of the facsimiles of Mendel's classical paper in your recent admirable "Festschrift" on the occasion of the Mendel centenary was particularly welcome. Alas, for a very sad reason. Early this century Professor Hugo Iliis, Mendel's main biographer, found the beautifully written manuscript "in a box full of papers destined for the flames." $\mathrm{He}$ remained the faithful custodian of this unique document until 1939, when, being a Jew and active Social Democrat, he had to leave Czechoslovakia at the

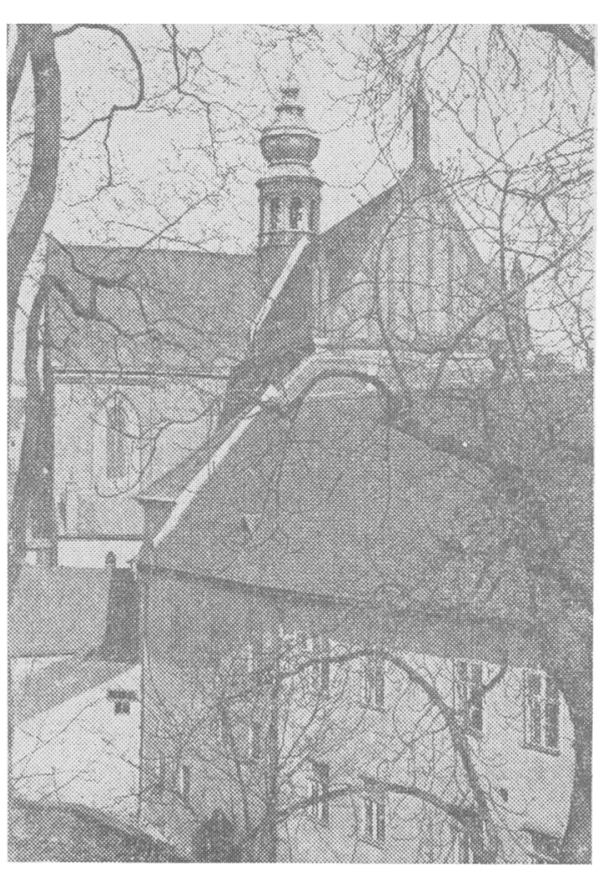

